\title{
Resistencias cotidianas en un asentamiento informal de la Zona Metropolitana de Monterrey
}

\author{
Marco Antonio Aranda Andrade*
}

Perfiles Latinoamericanos, 26(52) | 2018

DOI: $10.18504 / \mathrm{pl} 2652-014-2018$

Recibido: 11 de julio de 2016

Aceptado: 18 de enero de 2018

\begin{abstract}
Resumen
La precarización y el estigma vividos en los asentamientos informales de la Zona Metropolitana de Monterrey, merman los derechos de personas que resisten cotidianamente para hacerse un lugar en la sociedad. En este artículo, se analizan los tránsitos entre espacios y actividades formales e informales atravesados por relaciones de dominación y resistencia en un asentamiento informal de la urbe. Habrá de observarse que, en estos tránsitos borrosos y negociables, hechos por la captura estatal, el estigma, el contacto ventajoso y la huida táctica, la gente se rebela contra la dominación y lucha interminablemente por su inclusión desde posiciones de desventaja atizadas por el Estado.
\end{abstract}

\begin{abstract}
The precarization and stigma experienced in the informal settlements in the Metropolitan Area of Monterrey, undermine the rights of people who resist every day in order to take a place in society. In this article, we analyze the transits between spaces and formal and informal activities crossed by relations of domination and resistance in an informal settlement of the city. We will see that, in these blurred and negotiable transits, made by state capture, stigma, advantageous contact and tactical flight, people rebel against domination and fight endlessly for their inclusion from positions of disadvantage fueled by the State.
\end{abstract}

Palabras clave: resistencias cotidianas, acción colectiva, Zona Metropolitana de Monterrey, asentamientos informales, marginalidad urbana, sociedad política.

Keywords: Everyday resistance, collective action, Metropolitan Area of Monterrey, squatter settlements, urban marginality, political society.

* Doctor en Ciencia Social con especialidad en Sociología por El Colegio de México. Profesor investigador de la Universidad Autónoma de Nuevo León, Instituto de Investigaciones Sociales | aranda.estudios@ gmail.com 
objetivo de este artículo es abordar las tácticas de resistencia cotidiana de los habitantes de un asentamiento informal ubicado en la Zona Metropolitana de Monterrey, México. La precarización de la vida, la estigmatización y los impedimentos al ejercicio de derechos en una ciudad con un marcado crecimiento desigual, son contestadas por acciones colectivas ocultas y abiertas de gente que busca hacerse de un espacio en la sociedad regiomontana.

Para debatir con los estudios en el tema que se enfocan en dicha zona y en otras latitudes, se cuestionarán dicotomías dadas por sentado (Estado-sociedad, público-privado), y se enfatizarán algunos aspectos de la era neoliberal con repercusiones en la ciudad, esto desde el marco de las resistencias cotidianas y sus categorías de captura, estigmatización, contacto y huida, útiles para analizar los espacios borrosos y las negociaciones permanentes que con distintos grados de visibilidad dicen mucho sobre un vínculo asimétrico que sanciona ordenamientos que, no obstante, son constantemente transgredidos de formas ocultas. La premisa del texto es que los pobres urbanos traman acciones colectivas que no siempre son impuestas ni necesarias de conducciones ajenas en contextos en donde la organización pública y sostenida es un lujo dada su posición de desventaja atizada por el Estado. En la búsqueda interminable de la inclusión, las resistencias son rebeliones contra formas de dominación que muchas veces se logran romper, pese a su carácter no heroico.

\section{La informalidad en dinámicas desordenadas de crecimiento urbano}

Las grandes ciudades hoy día se caracterizan por ser lugares en los cuales se reproducen patrones de desigualdad y exclusión acentuados gracias a procesos de urbanización incontrolada. Metrópolis de tamaño medio, como Monterrey, son las que se han expandido más en los últimos años (ocDE, 2015; Davis, 2006). De acuerdo con Álvarez \& Delgado (2014), la fragmentación citadina actual se manifiesta en la crisis de vivienda y de la provisión de servicios urbanos, en el aumento de la pobreza, así como en la disputa por territorios llevada a cabo por inversionistas beneficiados por distintos gobiernos. En este contexto, la marginalidad urbana y sus consecuencias son el resultado de un crecimiento económico desigual que precariza todavía más a los sectores desprotegidos (Wacquant, 2010). La marginalidad urbana conduce a la fragmentación biográfica, a la inseguridad laboral, a la precarización de la vida, a la estigmatización y a la penalización de la pobreza misma (Dubet, 2015; Wacquant, 2010).

Este conjunto de desventajas excluye, argumenta Ziccardi (2008), a millones de personas del ejercicio efectivo de sus derechos básicos. El Estado, además de 
desentenderse cada vez más de la regulación del acceso y uso de la tierra urbana, abandona progresivamente cierta regulación de la vida de las clases populares. La "mano izquierda" del Estado es desplazada por su "mano derecha", aquella que gobierna la seguridad y su policía, el ejército, la justicia y la cárcel (Wacquant, 2010). El peso de esta intervención estatal se atestigua sobre todo en tipos particulares de conjuntos poblacionales que han recibido diversos nombres: "favelas, villas miseria, callampas, colonias populares, barriadas [...]" (Ziccardi, 2008: p. 16). Las mal llamadas minorías que ahí se agrupan, se convierten en las clases peligrosas (Dubet, 2015). La desigualdad, producto del ordenamiento sociocultural neoliberal, no solo atrofia las capacidades de personas situadas en la parte más baja de la asignación intencional de distintas desigualdades (Therborn, 2016), sino que somete a estas poblaciones a una liminalidad que las ubica en regímenes de invisibilidad o hipervisibilidad convenientes a los fines de un cierto tipo de economía política (Wacquant, 2014).

De manera notable, estas poblaciones marginadas han quedado fuera del mercado legal de la tierra, particularmente en América Latina (Clichevsky, 2006). La reestructuración de la economía y las reformas del Estado con sus medidas de ajuste, sus devaluaciones y privatizaciones (Davis, 2006), privilegian el uso especulativo del suelo, lo que lleva a los pobres a buscar asentarse en zonas abandonadas del centro de las ciudades, en los desarrollos inmobiliarios abandonados en la periferia, en la invasión de terrenos o en las zonas de riesgo ecológico. Estas acciones, en donde intervienen los pobres, distintos gobiernos, actores económicos privados y diferentes estratos de la población en general, han mantenido vigente un viejo debate en torno a la formalidad e informalidad de estas maneras de vivir.

Entonces, además de compartir una situación estructural de desigualdad que los excluye de sus derechos, incluidos el de la vivienda digna y el del disfrute y participación del espacio público (Pérez \& Castellanos, 2013), los pobres se debaten entre la pertenencia o adscripción —impuesta o asumida - a espacios formales e informales de las ciudades. En América Latina, los asentamientos informales representan el espacio predominante de desarrollo urbano en las grandes urbes (Torres, 2009). Gran parte de la literatura clasifica como informales estos asentamientos según la imposibilidad de sus habitantes para acceder a los mercados de la tierra y de trabajo, ambos pautados según reglas jurídicas cuya inobservancia sitúa a esas personas en la irregularidad o la ilegalidad. La realidad de estos asentamientos en la expansión horizontal y descontrolada de las ciudades ha ido cambiando al atravesar etapas que van de las consideraciones patológicas (cánceres urbanos) a las proactivas (AldreteHass, 1985), sean estas de carácter militante (Aldrete-Hass, 1985), clientelar (Quijano, 1972; Lomnitz, 1975; Montaño, 1983) o neoliberal (Turner, 1968). 
Unos de los avances de la literatura contemporánea en el tema consiste en desmitificar la supuesta dualidad irreconciliable que pudiera establecerse entre la formalidad, remitida a las normas convencionales y el statu quo protegido por los Estados, y la informalidad, asociada a la irregularidad y a la ilegalidad (Duhau, 2003; Herzer et al., 2008; Torres, 2009). En la época de los tiempos neoliberales, muchos individuos que habitan este tipo de asentamientos pueden formar parte, de modo simultáneo, de sectores formales e informales; pueden bien tener un empleo en el sector formal de la economía y vivir en un asentamiento informal o viceversa.

Para Roy (2011), la informalidad es un idioma de la urbanización que tiene un componente espacial indispensable. Este autor señala que las formas actuales de producción del espacio (suburbio-barrio bajo, por ejemplo) son expresiones del poder de clase que, en manos del Estado, designa qué es formal (legítimo) y qué queda por fuera, en el terreno de lo criminal y estigmatizado. Pero ante los intentos de control, la dicotomía se vuelve problemática por el tránsito espacial continuo entre lo formal y lo informal; la separación es en realidad una frontera móvil y contingente que supone el estar incómodamente dentro y fuera de lo establecido (Harms, 2011). Pertenecer o no a estas categorías en las cuales se intensifican las relaciones de poder y resistencia (Mezzadra \& Neilson, 2012) expresa el alcanzar también logros materiales, construir identidades y hacerse de un lugar en la misma sociedad (Bayat, 2000). En suma, lo formal y lo informal se vinculan de maneras distintas gracias a acoplamientos e interrelaciones que no dejan de presentar relaciones conflictivas (Herzer et al., 2008). ${ }^{1}$

Como señalamos recién, en estos tránsitos entre espacios y actividades porosas, el papel del Estado es central. ${ }^{2}$ Wacquant (2010) anotó que la respuesta del Estado a la marginalidad urbana, concentrada particularmente en estos

1 Como han señalado Alsayyad \& Roy (2006), no se trata de ver en las ciudades dinámicas simples de exclusión (informalidad)-inclusión (formalidad), sino lógicas de gobierno de poblaciones en donde la falta de regulación de personas y territorios constituye otra forma de regular. En el caso de la informalidad, no hay ausencia del Estado sino intervenciones gubernamentales constantemente negociadas mediante modos visibles e invisibles de regulación, según habrá de verse.

2 La centralidad del Estado, entendido este como un principio de organización del consentimiento que opera a través de actos de teatralización institucional con efectos de poder expresos en clasificaciones sociales normadas (Bourdieu, 2014), dice mucho sobre las dinámicas de dominación y resistencia. Se sabe que el Estado tiene cierto monopolio sobre la creación de representaciones con pretensión universal (regular e irregular, en este caso), las cuales son interiorizadas por quienes domina. La fuerza de los ritos de las instituciones, al separar lo social en nombre de toda una colectividad (formal-informal), acentúa la naturalización de las clasificaciones que los dominados interiorizan por medio de innumerables relaciones y pasajes de socialización. La aceptación del orden y del sometimiento, pese a generar inconformidades y desacuerdos, es tan fuerte que es difícil de socavar. La resistencia a esta violencia simbólica no es las más de las veces liberadora, ya que no depende solo de la voluntad, sino un intento contra un fuerte efecto de poder que opera estructuralmente para inscribirse con fuerza en las cosas y cuerpos (Bourdieu, 
asentamientos, cuenta con distintas alternativas, las cuales, a pesar de estar concebidas para sociedades del centro, pueden extenderse a las periferias. Entre tales alternativas está la extensión de programas bienestaristas de cobertura a la población que, pese a su actual focalización y pérdida de universalidad, buscan desmovilizar o desarticular las potenciales protestas de los pobres, junto con otras medidas tecnificadas de gestión urbana (Garnier, 2006). La otra vía conduce directamente a la criminalización o invisibilización, expresas en la exclusión de los pobres de la escena pública (Wacquant, 2010). Generalmente, ambas alternativas se combinan y, de cara a ellas, surge también la resistencia.

\section{Infrapolítica y resistencias cotidianas}

Uno de los principales problemas que presentan varias investigaciones acerca de los marginados urbanos asentados informalmente, refiere a la noción que poseen de su accionar colectivo. Desde los primeros estudios dedicados a los asentamientos y al análisis del clientelismo, la acción colectiva de los habitantes de esas poblaciones ha reproducido ciertas lecturas predominantes en el campo. En el libro de Montaño (1983), por ejemplo, a los pobres de la ciudad se les trata como algo que debe ser comandado o conducido hacia fines políticos, cuestión que no solo niega a los actores conciencia política autónoma, sino que les atribuye disposiciones estáticas de este carácter que no cambian en el tiempo.

En investigaciones recientes, la acción colectiva de los pobres de los asentamientos es vista como desfavorecida en la participación del ámbito público (Herzer et al., 2008), dependiente de la presencia continua de problemas graves, de la aparición de liderazgos enérgicos o de fuerzas externas como las organizaciones no gubernamentales (ONG) que la catalicen y subordinen (Lombard, 2012); en resumen, los pobres necesitan ser ilustrados o conducidos por un agente o causa externa. Incluso la autonomía que estos actores son capaces de alcanzar tras sus esfuerzos colectivos (tomar calles, defenderse conjuntamente, apelar a los medios de comunicación, iniciar proyectos propios) se menosprecia al condenarla a la invisibilidad (Márquez, 2008).

La otra cuestión problemática con estos estudios refiere a la separación monolítica entre el Estado y la sociedad realizada por muchos autores. De vuelta a los estudios pioneros como los de Montaño (1983), se observa la separación que pone, por una parte, a una maquinaria gubernamental que utiliza la

2000). La ruptura con esta violencia, según Bourdieu, vendría solo de la transformación radical de las condiciones sociales que la producen, punto de discusión al que se volverá más adelante. 
negociación y la transacción con los pobres para evitar conflictos y, por otra, a personas que no tienen otra opción que usar los canales políticos abiertos por el Estado para satisfacer sus demandas. A pesar de que se reconoce que el Estado está diferenciado según agentes e instancias, las acciones colectivas de la gente de los asentamientos se piensa como impedida por una gran instancia que criminaliza y estigmatiza (Pereira, 2008). A manera de efecto paradójico, esta maquinaria que excluye mientras precariza, se ve como la responsable de garantizar el desarrollo, la igualdad y la dotación de condiciones necesarias para el ejercicio de derechos (Márquez, 2008).

Estudios recientes han resuelto y abordado esta paradoja. Las nociones de "espacios grises" de Yiftachel (2009a, 2009b), de "movilidades laterales" de Kessler \& Merklen (2013) o de "bordes sociales" de Harms (2011), se centran en las muchas veces incómodas zonas pseudomarginales o borrosas que están compuestas de contenciones o arreglos estratégicos que ocurren entre intentos movedizos de inclusión y exclusión urbana. Las luchas interminables de poblaciones excluidas por pertenecer o ser reconocidas e incorporadas, están hechas de miles de pequeños movimientos, no siempre articulados o coordinados, que ocurren en espacios de supervivencia insertos en una planificación urbana diseñada para manejar las profundas desigualdades sociales de esta época. Estos tipos de acciones no heroicas, enfocadas en la supervivencia (Yiftachel, 2009b; Bayat, 2000), proliferan en regímenes urbanos de gubernamentalidad compuestos por innumerables formas de negociación con distintos grados de visibilidad (Alsayyad \& Roy, 2006). El vínculo entre el Estado y la sociedad es aquí, pese la contingencia que pueden dar ciertas batallas por la inclusión, profundamente asimétrico, pendiente del juego de las representaciones y categorías producidas para sancionar lo formal y lo informal desde el Estado y desde las propias personas, afirmación esta que guarda resonancia con los planteamientos acerca de la violencia simbólica y del consentimiento hechos por Bourdieu.

Por último, del lado de los pobres, se identifican en otros estudios dificultades centradas en la reproducción de distinciones y desigualdades entre los propios marginados, quienes socavan su solidaridad e impiden su articulación política colectiva (Wacquant, 2010; Appadurai, 2007; Dubet, 2015). La gente de los asentamientos es también, en esta visión muchas veces victimizante, objeto de la dominación ejercida por los dueños de los predios que invaden, por las ONG que desincentivan la movilización, por grupos criminales, por agencias inmobiliarias que especulan con la tierra o por liderazgos locales cooptados por otras fuerzas (Davis, 2006).

En el fondo de muchos paradigmas explicativos e investigaciones empíricas, encontramos, pues, la validación de un orden concreto consistente en institucionalizar la rabia y presentar las protestas de manera coherente o razonada; se 
trata de ordenar el descontento, de hacerlo legible (Scott, 2013), aun teóricamente. Gran parte de la acción colectiva de la gente de los asentamientos, como se mostrará, transcurre en la cotidianidad desgobernada a través de prácticas de resistencia cuya importancia no está lo suficientemente contemplada. En aras de complejizar la lectura sobre las acciones colectivas de los pobres, así como el tratamiento de las dicotomías Estado y sociedad y formal e informal, tal como lo han hecho estudios recientes sobre el clientelismo político (Auyero \& Benzecry, 2017; Holland, 2016; Hurtado, 2014; Silva, 2014), nos valdremos del análisis de prácticas de resistencia cotidiana desplegadas en el asentamiento de una urbe de tamaño medio en expansión desordenada, comenzando entonces con anotar algunas precisiones de carácter teórico que dialoguen y se nutran con las posturas revisadas hasta ahora.

Para comenzar, cabe indicar que el concepto resistencia es en sí mismo problemático. En la amplia revisión que realizan Hollander \& Einwohner (2004) sobre el tema, se expone que la resistencia, según las distintas aportaciones en torno al concepto, puede ser física o material, violenta o desplegada en pequeños trabajos ocultos, individual o colectiva, extendida o limitada y con diversos grados de coordinación. A diferencia del estudio de las formas convencionales de resistencia política abierta (visible), tal y como se hace en la mayoría de los enfoques en el campo de la acción colectiva y los movimientos sociales, nos enfocaremos principalmente aquí en la investigación de las resistencias cotidianas, ocultas ante el ojo de quienes dominan, pero no así a los ojos de quienes las llevan a cabo y las investigan. De la tipología de Hollander \& Einwohner (2004), nos centraremos entonces en el análisis de dos clases de resistencia: la definida como encubierta, esto es, de los actos intencionales no reconocidos como tales por sus opositores, pero sí por actores y observadores; y la que se define solo por observadores y no se reconoce como tal por quienes la llevan a cabo y sus opositores. Esto último es así porque la interiorización de las categorías impuestas por la violencia simbólica estatal —que define qué es legítimo o formal y qué es ilegal o ilegítimo - es tal, que impide ver su potencial de ruptura. Este sesgo en apariencia político tendrá su punto de apoyo en la revisión de otras posturas teóricas, según se verá en breve.

En el estudio de este tipo de resistencias, cabe asimismo señalar que estas acciones colectivas cotidianas y veladas que podemos inferir en los asentamientos informales, puede situarse también como una subespecie de esa acción colectiva abierta, pública y sostenida que no ha sido reconocida suficientemente como tal (Scott, 2013). La resistencia visible y pública no está divorciada de la encubierta. Pero muchas veces se presenta así por la incapacidad de reconocer, entre los académicos y analistas incluso, el desorden del mundo real, sujeto a constantes trabajos de ordenamiento, regulación, jerarquización y formalización 
(Scott, 2013). Los modos de resistir a estos intentos de control, que de manera general son disfrazados, silenciosos, dispersos e invisibles al ojo público, han sido objeto de una serie larga de trabajos inspirados inicialmente en las aportaciones de James Scott y Michel de Certeau.

Los supuestos de Scott $(1985,1998,2009,2013)$ acerca de lo que denomina infrapolítica, como el evitar ser gobernado sin excluir por ello el mantener contactos ventajosos con el Estado o con segmentos de las clases dominantes, se concentran en definirla como los actos de desobediencia silenciosa y anónima llevados a cabo por formas de vida estigmatizadas en contextos en donde el desafío público resulta muy riesgoso. Para Certeau (1984), las tácticas de resistencia cotidiana ocurren como transformaciones infinitesimales dentro del orden dominante, modos de operar cuyo propósito es adaptarlo a los intereses y reglas de quienes resisten. ${ }^{3}$

Las resistencias cotidianas, infrapolíticas o subalternas, generalmente ejercidas por gente excluida o marginal cuyas acciones muchas veces se enfocan en la satisfacción de necesidades inmediatas, representan un tipo de lucha social que puede asociarse también a la aceptación de la subordinación (Modonesi, 2010), a la apatía (Dube, 2001) o a la sumisión (Piven \& Cloward, 1979); posiciones sociales estas que no obstante se pueden socavar resistiendo (Butler, 2001; Vinthagen \& Johansson, 2014). Estas prácticas ocultas pueden asimismo implicar relaciones de dominación. Pese a que mediante las formas de resistir se pueden quebrantar las relaciones de poder, aspecto que relativizaría la teoría bourdiana, existen prácticas que reproducen jerarquías y exclusiones entre quienes las llevan a cabo, lo que les atribuye un carácter ateleológico alejado de una visión necesariamente emancipatoria; es decir, en ellas ni el poder ni la resistencia ganan, sino que los sujetos aprenden tanto tácticas de resistencia como de poder que después emplearán con distintos motivos de manera situacional (Vinthagen \& Johansson, 2013).

Ya que generalmente las resistencias cotidianas son de manera recurrente situadas en el piso de la sociedad (Scott, 2009) y ejercidas por personas con necesidades apremiantes (Bayat, 2000), sus prácticas se despliegan en contextos de

3 Estos supuestos obtenidos de investigaciones acerca del campesinado o sobre las artes culinarias, han generado críticas importantes. El evidente sesgo cultural y geográfico del trabajo de Scott, por ejemplo, haría difícil ver la utilidad de su trabajo en Asia para México y América Latina. En términos analíticos, por otra parte, valen las críticas que Tilly (1991) hizo respecto de las dificultades que en el trabajo de Scott impiden ver la dominación entre los mismos subordinados, así como el alcance de sus acciones; mientras que las de Gal (1995) referían a las posibles omisiones de otros elementos como contradicciones y contradiscursos que pueden aparecer en esas mismas poblaciones. En este artículo, trataremos de controlar estos señalamientos y estirar el trabajo de Scott hasta donde sea posible de acuerdo con las exigencias teóricas de otros aportes y las del propio referente empírico. 
dominación concretos en los cuales se trabaja y arrebata terreno a los intentos de ordenación dominantes. Las resistencias cotidianas crean espacios de lucha en el campo del enemigo (Certeau, 1984), espacios que deben ser constantemente ganados y defendidos mediante repertorios de tácticas de resistencia. Debido a que la lucha social depende en gran medida de factores estructurales por ser ejercida desde posiciones sociales débiles (Piven \& Cloward, 1979), se espera que quienes la practican encaren obstáculos mayores (la estigmatización, la desacreditación, la exclusión o la represión) para desplegar sus tácticas.

Como parte de los factores estructurales que ciñen a la resistencia y reproducen la dominación, se encuentra el Estado. De acuerdo con Scott (2013), el Estado siempre ha frustrado la organización de los marginados y de su rebeldía pública. Para este autor, la mayor parte de las clases subordinadas "históricamente, han carecido del lujo de la organización política manifiesta, lo que no les ha impedido trabajar en complicidad y de forma microscópica, cooperativa y multitudinaria en el cambio político desde abajo" (Scott, 2013: p. 20). Esta lectura va en contra de las visiones dominantes que quieren entender la acción colectiva como el producto de conducciones externas a los grupos o como esfuerzos organizados coherentemente (Diani, 2012). La estructura de esta resistencia, que solo en ocasiones puede visibilizarse y engancharse con otros tipos de acción como aquellos propios de los movimientos sociales, es informal, transitoria y ajena a la lógica de la institucionalidad formal (Scott, 2013). La divisibilidad y la dispersión, continúa el autor, son sus principales atributos.

Las prácticas de resistencia en la vida informal de los asentamientos se pueden pensar como tipos de existencia social, diremos aquí, caracterizados por la autonomía, la flexibilidad y el pragmatismo, en donde la sobrevivencia y el desarrollo propio ocupan un lugar central (Bayat, 2007). El apoyo a los proyectos estatales, el relacionarse con las clases que les excluyen o el buscar mantener al Estado y a esas clases fuera, serán acciones tácticas de carácter pragmático. El pertenecer a una sociedad política (Chatterjee, 2004), distinta a las concepciones normadas jurídicamente de la sociedad civil, implica trasgredir muchas veces la legalidad en busca de vivir y de reivindicar precisamente los derechos ciudadanos que no les son reconocidos debido a su ilegalidad.

Ante esto, el Estado y sus instancias reconocerán algunas demandas que no obstante no aceptarán que representen derechos en forma. Lo que ocurre, anota Chatterjee (2014), son negociaciones en ambientes de expectativas en los cuales se supone que el Estado atienda a los pobres mientras los usa a conveniencia. En los términos del clientelismo clásico, se puede decir que existen manipulaciones recíprocas entre los pobres y los agentes e instancias del Estado (Montaño, 1983). Además de que el Estado y los grupos que se alían con los marginados 
deben actuar para renovar su legitimidad como instancias que trabajan en favor de su bienestar (Chatterjee, 2004), estos también los usan para desempeñar ciertas funciones como las de componer clientelas (Holland, 2016) o las enfocadas en la realización de trabajos de cuidado u ocupaciones consideradas indignas o de poca importancia (Appadurai, 2007). En el presente artículo, este uso dominante será empleado bajo la categoría de captura.

Encontrarse al margen de los procesos económicos y políticos formales, lo cual implica estar muchas veces incómodamente dentro y fuera en la media en que se transita entre distintos espacios y actividades, es vivir todavía en los espacios intersticiales del radio urbano (Lomnitz, 1975), en donde la estigmatización es un hecho recurrente. En México, la marginalidad informal ha estado asociada a esa visión patológica del hábitat urbano, en la cual la dimensión racial y de clase es determinante para profundizar el estigma (Davis, 2006). La violencia que imprime la estigmatización a la vida cotidiana de los asentamientos a menudo involucra la búsqueda de discursos y prácticas que permitan asegurar la continuidad de la vida de tal modo que se pueda soportar lo insoportable (Pereira, 2008). En este trabajo, al exponer más adelante la evidencia empírica que lo sustenta, recurriremos a esta categoría de la estigmatización como un elemento que disminuye la capacidad colectiva de la gente para operar sobre las fuerzas que les descalifican (Wacquant, 2010).

Pese a las capturas estatales y a la estigmatización, las formas dispersas, ocultas y móviles de la resistencia cotidiana implican también dos actos de agencia política: el contacto ventajoso con quienes excluyen (para obtener beneficios materiales, territoriales y de reconocimiento) y la huida de la dominación, la que implica el emprender proyectos autónomos que buscan mantener tanto al Estado como a los estratos dominantes de la sociedad, fuera. El reconocerse y asumirse como clientelas, sea acríticamente o no, y el emprender acciones colectivas de cara a la supervivencia (Soldano, 2008), dependerá de las situaciones por las cuales atraviese la gente de los asentamientos. Los modos de planeación comunitaria frente a la lógica formal (Lombard, 2012), así como los espacios de autonomía que pueden alcanzarse usando o no contactos ventajosos para solucionar problemas urgentes, socavan las estrategias de captura estatal y estigmatización social. Contacto y huida conforman entonces otras dos categorías centrales para este artículo.

Las resistencias cotidianas, colectivas, ocultas, móviles, cómplices, microscópicas, dispersas e informales, condicionadas por la captura estatal y la estigmatización, buscan un lugar complementario en el estudio de las acciones colectivas públicas, abiertas y duraderas. El contacto táctico y la huida del dominio pueden anteceder, acompañar o proseguir los repertorios de protesta de actores colectivos más visibles. A continuación, se presentará evidencia empírica que ilustre 
el funcionamiento de las categorías expuestas con el objeto de dar cuenta de hechos que forman parte de la vida urbana marginal hoy día.

\section{La Zona Metropolitana de Monterrey y el asentamiento Bellavista}

En México, la Zona Metropolitana de Monterrey (zMM), que concentra a más del $80 \%$ de la población del estado de Nuevo León, se caracteriza por ser un espacio urbano desigual con altos niveles de inseguridad, contaminación del aire y mala calidad de muchos servicios públicos (OCDE, 2015). La metrópoli, cuyos bordes crecen a una velocidad de hasta un millón de hectáreas cada año (Ochoa, 2016), presenta una desigualdad social considerable que acentúa los problemas propios de una ciudad de tamaño medio con una dinámica demográfica, económica y urbana desbordada (osln, 2015). Como otras ciudades del país, la ZMM adolece de planes de crecimiento metropolitano efectivos, aunados a la ausencia de una asociación entre tareas de planeación y actividades de gestión pública, especialmente en lo que se refiere a asentamientos informales (García, 2001; Valles, 2015). ${ }^{4}$ De acuerdo con algunos autores, en la ciudad un asentamiento irregular puede ser asociado a la "ilegalidad en las formas de posesión de la tierra y/o a los usos permitidos del suelo" (Valles \& Infante, 2014). Además de la cuestión jurídica y de los problemas de acceso a los mercados de trabajo, estos asentamientos resultan ser una clara expresión de la incapacidad del Estado y del mercado por responder a la demanda de vivienda, insatisfecha en la entidad debido a la insuficiencia de reservas territoriales o a los altos costos de la urbanización (Valles \& Infante, 2014).

Las formas usuales de ocupación de la tierra en la entidad desde la década de 1960 han involucrado a los posesionarios, a los dueños de los predios, a las instancias gubernamentales reguladoras y a actores políticos como alcaldes, partidos o centrales obreras (Valles \& Infante, 2014). Las ocupaciones han ocurrido a través de la movilización y organización política (de sindicatos, estudiantes o de actores populares como Tierra y Libertad), de las autoinvasiones (concertadas por los propietarios de los predios) o del apoyo a urbanizadores privados (García, 2001). En estos procesos, las instancias del Estado, ante la imposibilidad de responder a las continuas crisis de vivienda, se han convertido en cómplices

4 Para inicios de la segunda década del nuevo milenio, la zMm contaba con 403 asentamientos irregulares, según los datos recopilados por Valles (2015). La autora menciona que alrededor del 10\% de la zMM ha crecido por esta vía. 
de estos fenómenos (Sandoval, 2008). ${ }^{5}$ No está por demás indicar que la pobreza y la migración interna son parte activa de este fenómeno, propio de una ciudad en la cual se ha tratado, consciente o inconscientemente, de ocultar la pobreza de su realidad social (Sandoval, 2008). Este aspecto se agrava más en la actualidad ante la expansión urbana de tintes privatizadores que genera enclaves - tanto de ricos como de pobres — "en un espacio interurbano muy diferenciado" (Aparicio et al., 2011: p. 194).

En la producción académica de las últimas décadas sobre estas poblaciones, específicamente, destacan los estudios acerca del capital social (Portales, 2014), de la participación conjunta (García \& Ramírez, 2006), de las estrategias de supervivencia (Sandoval, 2008), de la organización autónoma (Zúniga, 1990), del trabajo comunitario (González, 2006) y del ya citado clientelismo, investigaciones que, de alguna forma $u$ otra, destacan a los pobres como productores activos de la ciudad y de nuevas relaciones sociales (Pozas, 1990; Zúńiga, 1990). Respecto a este rico cuerpo, nos alejaremos de algunas dicotomías planteadas en estos estudios (Estado-sociedad), por ejemplo, y nos centraremos de manera crítica en la era neoliberal, además de contribuir con el marco de las resistencias cotidianas, teóricamente distinto a los empleados en las investigaciones referidas.

\section{Bellavista}

El asentamiento informal en el cual se desarrolló la investigación empírica cuyos resultados se emplean para este artículo, ${ }^{6}$ se encuentra en el municipio de Santa Catarina. Este municipio, según las últimas cifras, cuenta con casi trescientos mil habitantes, que representan cerca del 7\% de la población total del estado. De acuerdo con la administración actual (2015-2018), el plan de desarrollo estima que 1173 ha están destinadas al uso habitacional. Dos mil cuatrocientas

5 A partir de la segunda mitad del siglo xx, se comienza a normar el crecimiento urbano y la construcción de vivienda en la ciudad. Desde los ańos setenta de ese siglo, como respuesta a las invasiones de frentes populares y a la intensificación de flujos migratorios, se empiezan a crear numerosos programas nacionales y estatales, así como instancias reguladoras de vivienda y crecimiento urbano; entre ellos, destacan la Comisión para la Regularización de la Tenencia de la Tierra y el Fomento Metropolitano de Monterrey (Fomerrey).

6 Este trabajo, que es parte de una investigación más amplia en curso, contempló la revisión documental de programas y actividades gubernamentales municipales, estatales y federales. Retoma también entrevistas semiestructuradas individuales y grupales con posesionarias, funcionarios municipales e integrantes de partidos políticos y organizaciones que intervienen en este tipo de asentamientos. Tanto el nombre del asentamiento como el de las personas cuyos fragmentos de entrevista se citan aquí, se mantienen bajo seudónimos por protección a las y los informantes. 
ha, por otro lado, se consideran áreas de conservación natural (no aptas para el desarrollo urbano), mientras que cerca de 3400 se suponen proclives para el crecimiento del municipio, según el documento Plan de Desarrollo Urbano, Centro de Población, 2000-2020.

El crecimiento urbano de Santa Catarina, acorde a la expansión de la ZMM, se acelera desde la década de 1960. Después de ser un territorio en donde surgen las primeras fábricas textiles y se conectan las primeras vías férreas con la frontera norte en el siglo XIX (Aparicio et al., 2011), Santa Catarina es a fines del siglo Xx una de las zonas industriales más importantes del área metropolitana. De acuerdo con el Ayuntamiento, la mayoría de las 270 colonias que integran la parte urbana tuvo su origen dentro de proyectos promovidos por el Estado o como asentamientos informales, aunque en fechas recientes el sector inmobiliario privado ha penetrado con mayor fuerza. Todo este crecimiento ha generado una serie de problemas. La posición de enclave minero (industria extractiva) del municipio ha provocado problemas de contaminación del aire y de salud pública.

Respecto a los terrenos no propicios para la urbanización, de acuerdo con la visión ordenadora de las administraciones, Santa Catarina ha enfrentado dificultades diversas debidas a las características del suelo y al trazado de áreas de conservación ecológica. La instalación de pedreras y la reubicación de asentamientos informales de zonas federales como la del río Santa Catarina o de áreas como las del arroyo El Obispo, cuentan como algunos ejemplos. Estos casos representan problemas de urbanización para un municipio del cual se espera aloje a casi quinientos mil habitantes para 2020. Según funcionarios de la Secretaría de Desarrollo Urbano y Ecología de la administración 20122015, entrevistados para este trabajo, existen centenares de familias cuyas posibilidades de regularizar su vivienda son difíciles. De acuerdo con sus censos, 2400 viviendas están ubicadas en áreas irregulares, hogares de los cuales cerca de ochocientos están con posibilidades de regularización; el resto, unos 1600, no cumplen con los requerimientos formales para hacerlo. El municipio identifica, además de los márgenes del río y del arroyo, las cańadas del nororiente y las zonas cercanas a las pedreras como proclives a la invasión.

La zona que interesa a este artículo está ubicada en la Sierra de las Mitras, un área poblada cuya pronunciada inclinación de terreno hace difícil su regularización, de acuerdo con los criterios normativos federales, estatales y del municipio. Como otros asentamientos irregulares, la población que invade carece de servicios urbanos regulares (pavimento, agua potable, drenaje, energía eléctrica). Sus habitantes provienen de entidades como San Luis Potosí, Zacatecas, Guerrero, Oaxaca, Veracruz, Hidalgo y trabajan, dentro o fuera de Santa Catarina, como obreros o en empleos no especializados del sector de servicios (pequeños 
comercios, ambulantaje, trabajo doméstico, ayudantías generales, intendencia), justo como pasa en otros municipios con población en la misma situación.

Bellavista, nuestro caso de estudio, es un asentamiento que se fundó hace veinte años como consecuencia de la reubicación de personas antes del paso de un huracán. Según varios testimonios, el entonces alcalde del municipio movilizó a la gente asentada informalmente en una cañada más arriba de la sierra, con el propósito de salvaguardarla y con la promesa añadida e incumplida de conceder terrenos en una colonia regular cercana tras el paso del meteoro. Bellavista comenzó con las carencias usuales de servicios, lo que generaba otros problemas como la contaminación provocada por aguas residuales de depósitos abarrotados, la pepena o la cría de animales de corral. El asentamiento ha enfrentado riesgos graves como las amenazas de incendios inducidos por la sobreacumulación de cableados de energía eléctrica. Al igual que en otros lugares informales del municipio, la gente de Bellavista ha carecido de servicios de salud, educativos y de transportación pública. Sin obviar los peligros que representa la temporada de lluvias y su consecuente crecida de arroyos, la cual provoca serias pérdidas patrimoniales, la gente sigue enfrentando los riesgos a la seguridad que invocan la violencia de género, el pandillerismo o las adicciones, encaradas cada vez más por las administraciones como problemas no de causas económicas y sociales, sino de seguridad, propios de la narrativa neoliberal (Wacquant, 2010; Garnier, 2006).

Como en muchos asentamientos, el trazado de las calles en Buenavista es sumamente irregular, condicionado también por la zona montańosa en la que está enclavado. El hacinamiento en los hogares es recurrente y la condición socioeconómica varía, según las actividades económicas de los habitantes. Al igual que en otros barrios, existe una pequeña "burguesía del asentamiento", con sus casas de dos plantas, fachadas terminadas, automóviles de modelo reciente y pequeños arbolados que flanquean los innumerables tejabanes vecinos hechos de cartón, plásticos, madera y otros desechos materiales destinados a la construcción. A pesar de que los suministros de agua y energía eléctrica no están formalizados, muchos servidores públicos de las compañías correspondientes cobran cuotas para poder acceder a ellos de forma colectiva. El camino al lugar de trabajo, cuando no se encuentra en las pequeñas tiendas informales del asentamiento, es largo y tortuoso, debido a las distancias e ineficacia de las pocas rutas de transporte que tocan sus bordes.

Tal y como sucede con otros asentamientos informales, su existencia oficial o invisibilidad en los mapas depende de la instancia gubernamental que se encargue de ellos. Bellavista puede existir en los planos que elabora el Instituto Nacional Electoral, pero estar ausente en los del municipio. La visualización cartográfica del asentamiento puede también hallarse como producto del traba- 
jo telemático de las compañías de software o territorial de los liderazgos locales o de las ONG que intervienen en Bellavista, las cuales contribuyen de manera diferenciada en los múltiples y ríspidos intentos de gobierno (Alsayyad \& Roy, 2006). En otras palabras, poner orden a la urbanización incontrolada implica empeños en disputa cuyo fin es hacer legible y gobernable el territorio vía la estigmatización o la captura.

\section{Estigmatización}

Las condiciones sociales en las cuales se encuentran los habitantes de Bellavista no dejan de ser objeto de la estigmatización. Los problemas de las aguas residuales generadas en los hogares, por ejemplo, abonan a la identificación de "focos infecciosos" hecha por funcionarios de gobierno, alimentados por la acumulación de basura; señala un funcionario: "Porque están acostumbrados a la pepena y si tú como gobierno les das un cuartito, olvídate, no van a poder tener su reguero de basura. Porque la gente no es mala, busca un medio ambiente al que ya está acostumbrada y a ellos se les hace muy normal andar entre la basura, entre el mugrero; entonces, ¿cómo les ayudas?” (Entrevista personal, septiembre de 2015). Cual "síntomas de una enfermedad social", los calificativos clasistas no dejan de acumularse en las entrevistas: analfabetas, alcohólicos, drogadictos, promiscuos.

Lo que los funcionarios expresan como "focos rojos" (grupos antisociales, apunta el programa municipal de desarrollo 2015-2018), implica para el Ayuntamiento una dificultad mayor que al nombrar así a los asentamientos les niega la dimensión social de vida colectiva y de ciudadanía. Por ejemplo, la cría de animales de corral, además de generar condiciones proclives para la insalubridad, provoca "un problema social porque yo como municipio tengo las quejas de los vecinos de atrás, que tienen una colonia regular, por olores; pero yo no puedo hacer nada, porque si voy y los levanto [desalojo] ipues me van a achacar que soy inhumano los de Derechos Humanos!, y qué se yo" (Funcionario del Ayuntamiento, entrevista personal, septiembre de 2015).

Los medios comerciales de comunicación también coadyuvan a acentuar el estigma sobre Bellavista. En una nota informativa de un reconocido diario local, se lee: "El silencio a lo largo de la hilera de tejabanes [...] es uniforme, es interrumpido de pronto por un grupo de niños que de lejos parecen niños normales, sin embargo, las manchas de sus caras revelan los estragos de la insalubridad" (Noriega, 1996). Personalmente, el estigma encarna en los señalamientos que reciben algunas personas de Bellavista al presentar demandas (servicios de salud, drenaje, electrificación) a las autoridades: "Ustedes son los posesionarios, 
quieren todo regalado. ¡Son los indigentes del cerro!" (Pamela, lideresa de un sector del asentamiento, entrevista personal, julio de 2015). Como en otras experiencias de la zona metropolitana, la mayor parte de las demandantes son mujeres, objeto de una discriminación marcada por el género que proviene tanto del Estado como de las mismas poblaciones patologizadas: "Señora, retírese a casa — dice el funcionario-, necesita usted un marido que le ponga las riendas" (Pamela, entrevista personal, septiembre de 2015). ${ }^{7}$

El descrédito entre la misma población de Bellavista muchas veces contribuye a colocar obstáculos a los intentos de las mujeres por conseguir sus demandas. Al impulsar acciones colectivas como las reuniones vecinales, en las cuales rondan los fantasmas de fraudes inmobiliarios pasados o la competencia entre actores -incluidos los representantes de los partidos políticos con presencia en el asentamiento-, se escucha: "Los hacemos [los proyectos colectivos] porque pues nosotras queremos, nadie nos mandó aquí, porque queremos estar bien, porque lo necesitamos. Es que luego empiezan a hablar, a decirnos que argüenderas y no sé qué, que solo queremos dinero y demás" (Bety, posesionaria, entrevista personal, septiembre de 2015).

7 Según anotamos previamente, las prácticas de resistencia suponen también el ejercicio del dominio entre quienes se rebelan. Un episodio significativo, que muestra las tácticas de resistencia de las mujeres que rompen los discursos ocultos que pueden mantener entre amigas o vecinas a las espaldas de los hombres del asentamiento cuando las oprimen, sucedió en una reunión en la cual Pamela, la lideresa, fue confrontada por un vecino descontento de las reuniones: "Vieja jija, me las vas a pagar por andar alborotando. ¿Y luego? __ contestó Pamela con sarcasmo_—. ¡Que te voy a matar!, nada más que te agarre sola. ¡Gracias! Así ya descanso porque estoy muy cansada de andarlos defendiendo — afirmó Pamela—. Nada más te digo una cosa: Si me pasa algo a mí, los pandilleros que me conocen van a ir a matarte” (Relato recabado en campo, agosto de 2015). Es necesario el estudio de más formas de resistencia abierta u oculta a la dominación masculina no solo en las reuniones sino en espacios como pueden ser los de la casa. Durante varios momentos de interacción entre hombres y mujeres se observa que los ámbitos de lo público — supuestamente el espacio masculino — y lo privado — el espacio femenino-, se intercambian o imbrican. Tras las reuniones (públicas), los esposos se congregan en privado para tomar acuerdos sin considerar las decisiones de la junta vecinal que encabezan, mayoritariamente, mujeres, lo que genera disgusto entre estas. Por otra parte, a pesar de que un tema público — como el trascurrir de una reunión — se discuta en casa y se consensue su seguimiento — hecho generalmente por la mujer — dada su importancia, muchas de las posesionarias del asentamiento asisten apresuradas a las reuniones por las coacciones de los esposos para cumplir con el trabajo doméstico, obligación que las mismas mujeres asumen como propia frente al mantenimiento del hogar y la familia. Durante las entrevistas, la centralidad del cuidado se manifestaba al identificarlo con la supuesta mayor sensibilidad de las mujeres por los problemas sociales, de acuerdo con las entrevistadas y en resonancia con otros trabajos con posesionarias (Rangel, 2003; Valles \& Infante, 2014). Es curioso notar que el trabajo público llevado a cabo por las mujeres — organizar y convocar a una reunión, por ejemplo_-, no sea percibido como político ya que se supone masculino. Finalmente, cabe notar que el trabajo reproductivo del cuidado fue ignorado o subestimado por investigaciones previas, en cuanto al sostenimiento de los ejércitos de mano de obra de reserva se refiere (Quijano, 1972; Montańo, 1983). 
Por otro lado, las relaciones del asentamiento con las colonias regularizadas es compleja y problemática. Así como los regulares pueden ser solidarios al permitir el colgado de cables eléctricos en los postes de sus calles, pese a la variación nociva de voltaje que eso provoca, pueden también contribuir a la estigmatización de los pobladores de Bellavista; menciona Rogelia: "Y lo que no se dan cuenta es que los indigentes y los cochinos, así como nos llaman todos los de allá abajo [los regulares], los que de veras tienen papeles, son ellos, nos avientan la basura. Tienen sus camionetas lujosas llenas de basura, vienen aquí y nos la tiran; vienen también de los mercados con sus costales y nos los avientan" (Posesionaria, entrevista personal, septiembre de 2015). ${ }^{8}$

El estigma que otorga un carácter violento a la vida del asentamiento - poblado según el Estado por grupos antisociales o por indígenas en condición de tránsito permanente, cuando no por seres sucios, ventajosos y peligrosos, de acuerdo con los vecinos regulares- contribuye a reproducir divisiones marcadas en la zona. En acciones colectivas como las reuniones vecinales, visibles solo para los habitantes y para algunas entidades como los partidos políticos, el descrédito entre habitantes también aflora, invisibilizando a las mujeres quienes, al dejar el espacio público de la reunión para sumirse en el trabajo reproductivo del cuidado, reprochan el dominio entre pares a espaldas de los maridos.

\section{Captura}

A pesar de la estigmatización y el descrédito, los intentos del Estado y sus instancias por ordenar a la población de Bellavista son recurrentes. Los constantes censos de población levantados en el asentamiento tanto por la Secretaría de Desarrollo Urbano del Municipio como por Fomerrey o el Instituto Nacional Electoral, son ejemplo de mecanismos administrativos que se echan a andar con el fin de controlar a la población del territorio. Estos intentos en donde lo formal y lo informal se difuminan y confunden - ¿ cómo beneficiar con una credencial electoral a alguien que está en una situación de poblamiento ilegal?-, no exime de problemas al Estado cuando se intentan coordinar tiempos e instancias federales, estatales o municipales.

8 Las relaciones cotidianas de este tipo de vecindad entre formales e informales acarrea que la diferenciación se dé en las mismas zonas residenciales (Quijano, 1972). La fragmentación social impide la articulación de demandas y movilizaciones ante necesidades apremiantes, como las referidas a los servicios de recolección de basura en el municipio o la implementación de programas sociales federales como Oportunidades o Prospera. Distinguirse por aspiraciones de clase al ser propietario de un predio legal, o por etnia, al no ser un migrante indígena del asentamiento, contribuye asimismo a la desarticulación social en el asentamiento. 
Una de las tentativas destacadas de captura es el uso conveniente de los habitantes de Bellavista en las relaciones clientelares que vienen de la mano de programas de política pública (Prospera), de organismos de asistencia social (como el DIF u ONG que trabajan en el asentamiento con acciones culturales o educativas) o del uso de liderazgos afiliados tanto al Partido Revolucionario Institucional (PRI) como al Partido de la Revolución Democrática (PRD); actos estos que recuerdan a la administración de la política bienestarista informal señalada por Holland (2016). Junto a estas estrategias operan también los recorridos territoriales del municipio que realizan la Secretaría de Desarrollo Urbano y la de Desarrollo Social y Humano o Fomerrey. ${ }^{?}$

Como parte de la captura se encuentran asimismo las negociaciones constantes del cuerpo estatal con los pobladores. En ocasión de la reubicación de un asentamiento ubicado en los márgenes del río Santa Catarina, pedida por la Comisión Nacional del Agua al municipio, surgió un problema recurrente manifiesto en los asentamientos: el posible desalojo de las pequeñas burguesías. Cuenta un funcionario del Ayuntamiento:

Nos exigieron el desalojo desde la federación, hablamos con los habitantes. Un señor ya tenía una casa de dos pisos, un terreno bastante grande. Nos dijo: "Y lo que le metí a mi casa, ¿quién me lo va a reponer? ¿Me vas a pagar el dinero?" No. Le dije que Fomerrey le daría un terreno porque ya no tendría casa. "¿Y como cuánto vale?”. Es el problema, nadie les dice que se pongan ahí y luego ya quieren exigirle a la autoridad y pues es un abuso de ellos por ponerse en donde no. $\mathrm{O}$ luego hay familias que viven en un solo tejaban y con la reubicación quieren tres o cuatro viviendas, una por familia, y cuando Fomerrey les otorga vivienda les mandan a otra colonia en otro municipio porque aquí ya no hay áreas reservadas, pero no les gusta, piden, se les da y regresan otra vez al asentamiento y como ya saben cómo funciona el sistema, de cómo vas y te posesionas y no te sacamos del sitio... Después venden las casas que les dieron y se traen a más gente para que haga lo mismo (Entrevista personal, julio de 2015).

Las negociaciones también se observan en los intercambios que entablan los pobladores del asentamiento Bellavista con partidos políticos al momento de canjear materiales de construcción o despensas por presencia en las casillas durante las elecciones, así como en la asistencia de gente de Bellavista a even-

9 Entre las acciones de estas instancias destacan, por ejemplo, la formación de comités de vecinos para la atención de demandas; la identificación y el trabajo con liderazgos populares; el despliegue de brigadas de salud o de empleo; la implementación de programas de cultura, deporte, protección civil o prevención del delito; el reparto de becas, así como la asesoría legal y psicológica a mujeres víctimas de maltrato. 
tos públicos de una ONG, cercana al PRD, que coadyuva al empadronamiento electoral de los habitantes del asentamiento. En estos actos de ordenamiento y control en donde lo informal y lo formal juegan interminablemente en un área gris (Yiftachel, 2009a), la inclusión y la exclusión transcurren como efectos de poder en una temporalidad incierta cuyo fin es manejar las desigualdades sociales a favor del mantenimiento del dominio estatal.

\section{Contacto y huida}

En un texto bastante difundido, Das \& Poole (2004) mencionan que los márgenes del Estado pueden ser extendidos o rehechos con el propósito de asegurar o condenar la vida de ciertas poblaciones. En ocasiones, los márgenes del Estado son recortados por los marginados al concebirlo como intrusivo e impositivo, lo que les otorga una capacidad autónoma de agencia notable. En Bellavista, la desaprobación de la corrupción estatal, manifiesta en el clientelismo y el contacto con la policía, por ejemplo, genera proyectos o iniciativas autónomas (escuelas comunitarias o comedores populares) que persiguen alejarse de compromisos o pagos de favores que se pactan con los partidos políticos mediante votos o con la presencia de gente para mítines o marchas.

Encontrarse en lo baldío, en lo ilegal, implica muchas veces el incursionar en iniciativas de organización popular que no son incentivadas desde fuera del asentamiento por fuerzas o factores reveladores u organizadores. Coordinarse para buscar satisfacer necesidades apremiantes, como puede ser el organizarse para levantar el tendido eléctrico o para abrir redes de drenaje, a menudo va de la mano de la exploración de opciones coordinadas de entretenimiento cultural que se imponen como condiciones a las organizaciones (ONG o iglesias evangélicas) que quieren llegar a trabajar al asentamiento. Los torneos de futbol, la organización de bailes o conciertos o la asesoría jurídica a la que puede accederse trabajando con las organizaciones aliadas, complementa acciones colectivas concertadas como la negativa a pagar por servicios públicos como el agua potable, obtenidos tras la movilización y la presión de las autoridades mediante la entrega de cartas, peticiones, mítines, confrontaciones públicas o de la ocupación de edificios públicos. El trabajo comunitario invisible al Estado por los servicios públicos se articula con la visibilidad que da el trabajar con las ONG, o con el reclamar al gobierno estatal o municipal un reconocimiento como ciudadanos con necesidades apremiantes.

Los repertorios de protesta llevados a cabo en Bellavista no fueron originalmente impuestos por organizaciones externas, sino por iniciativa de los primeros vecinos, quienes obtuvieron después aprendizajes políticos al colaborar con 
partidos y asociaciones políticas, mismas que posteriormente trabajarían territorialmente a cambio de beneficios como los votos. En el caso de Pamela, lideresa de un sector del asentamiento, su colaboración pasada con el Partido del Frente Cardenista en actividades como la regularización y escrituración de predios, la organización de cooperativas, la gestión de servicios públicos o la elaboración de peticiones, ha resultado significativa al momento de movilizar a la gente nueva en el asentamiento; señala esta lideresa: "Sabemos que necesitamos a los de arriba [los partidos] para que hablen por nosotros. Nosotros tenemos derechos; yo le digo a la gente adónde podemos ir a patear puertas" (Entrevista personal, julio de 2015). ${ }^{10}$ Acciones espontáneas, ocultas al ojo público del Estado, llegan a complementarse con formas organizadas emprendidas por actores con experiencia en los temas que usan de manera fructífera al mismo Estado.

Ahora bien, el sacar partida de contactos ventajosos con el Estado o con sectores sociales para satisfacer necesidades apremiantes de manera táctica, se expresa en algunas ocasiones en el aprovechamiento de cargos públicos, como la participación de Pamela en una candidatura de elección popular, en la suscripción de programas federales como Prospera y en el impulso de acciones con instituciones de educación superior, como las actividades deportivas que en el asentamiento realizaron alumnos de la Universidad de Monterrey. Estos emprendimientos colectivos se traducen en contactos de los que se puede echar mano después, sea para satisfacer necesidades de los habitantes o para obtener protección ante adversarios políticos, como en el caso de las disputas de Pamela con otras lideresas del asentamiento. Entrar en contacto con el exterior del asentamiento implica asimismo echar mano de la policía para intervenir en situaciones de violencia doméstica o para presionar legalmente a adversarios acusados de fraude inmobiliario.

En los márgenes del Estado, las tácticas se despliegan muchas veces en el campo del enemigo. Pamela no solo ha aprovechado a las representantes vecinales de un partido político rival en Bellavista, volviéndolas aliadas a cambio de reconocerles poder territorial, ${ }^{11}$ sino que ha desarrollado una estructura

10 En efecto, Pamela también ejerce poder en su grupo de vecinas y áreas de influencia territorial desde su posición de lideresa, y puede castigar con relegar de cargos a quienes colaboran con ella en caso de no sumarse a sus iniciativas. En cierto sentido, Pamela y otras lideresas, tal y como hacen los partidos en el asentamiento, buscan transformar la indignación, el dolor o las inconformidades de los habitantes en proyectos coherentes que suponen el representar a los marginados, muchas veces para beneficio propio (votos o consolidación de posiciones de poder en la lucha territorial del asentamiento).

11 Es importante señalar que las mujeres definen constantemente principios de convivencia vecinal ante la ausencia de regulación estatal, lo que les permite ejercer cierto poder sobre el territorio. En el caso de las zonas que recién se invaden, propiciar la vecindad pacífica entre personas que provienen de diferentes estados de la república, supone el establecer reglas de convivencia como la de que nadie debe invadir con su tejaban los trazos de las incipientes calles o la que prohíbe tirar aguas residuales a casas aledañas. 
organizativa informal, microscópica, móvil y simplificada que cubre casi todo el asentamiento. Gran parte de los logros organizativos del grupo de Pamela es posible por la elaboración de peticiones a las autoridades, la solicitud de intervenciones gubernamentales para dirimir conflictos en el asentamiento, la gestión de servicios públicos, el trabajo territorial y la planeación de tácticas de presión política.

Este conjunto de acciones colectivas es posible por el trabajo a pequeña escala y espaciado que surge en las reuniones de este grupo de mujeres que muchas veces tiene claro que los proyectos deben echarse a andar sin gobiernos o partidos. En ocasiones, la participación de los vecinos se pide a través de la presentación de propuestas, sea en las reuniones vecinales que organiza el grupo o mediante el arrojo de piedras envueltas con un papel escrito a los patios de las casas de las integrantes, vehículos que sirven de medios anónimos a la petición. Los grupos de teatro, las brigadas de concienciación contra el maltrato doméstico y el trabajo con niños de Bellavista, son acciones posibles gracias a la articulación de Pamela con sus representantes en cada manzana del asentamiento, quienes organizan pequeñas reuniones que alimentan a las generales, todas ellas de corta duración dada la presión de volver a casa para cumplir con las actividades del hogar o con las expectativas de los maridos sobre los horarios en los que creen que una mujer debe andar sola o con los hijos por las calles.

Las disidencias entre las mujeres del grupo pueden airarse en las reuniones, en las que se escucha el "Yo no soy mandadera ni gente de nadie", frase que alude a la independencia que las mujeres de las incipientes manzanas de Bellavista guardan respecto de Pamela. Estas personas, que han sido los vínculos esporádicos con los vecinos según los proyectos y que igualmente han fungido como observadoras de casilla para un partido político, se organizan por comités de manzana o zonales, convocan a juntas vecinales e impulsan y consensuan acuerdos entre vecinos. El poder de las mujeres se ejerce en los permisos que pueden dar a nuevos vecinos que quieran incorporarse a los proyectos, previa consulta con esa comunidad de participantes.

Resulta interesante notar que muchas de estas formas de organizarse para resistir se conciben como el reclamo y el ejercicio de derechos (a la vivienda, a la calidad de vida, a los servicios, a la no discriminación): "No es nuestro modus operandi como nos dicen en el municipio, lo hacemos porque el Estado es el que está incumpliendo su tarea" (Pamela, en reunión vecinal, agosto de 2015). Esta sociedad política (Chatterjee, 2004) a la que se protege desde el Estado en la época de lluvias con brigadas de protección civil, a la que se le busca regularizar o reubicar y a la que se le niegan los derechos por estar en una situación de ocupación ilegal, encuentra finalmente algún tipo de estatus: "Por un lado no cumples lo que te marca la ley [desalojarlos] y, por otro, como son ciudadanos 
de tu municipio, tienes también que tratarlos de una cierta manera y ayudarlos" (Funcionario del municipio, entrevista personal, septiembre de 2015).

Por último, la acentuada movilidad de la población en Bellavista, con sus tránsitos migratorios interminables y precarizados, impide que el Estado controle y mapee la población completamente y que Pamela y otras lideresas consoliden bases sociales en el territorio. Pero sea mediante el avance silencioso en la construcción de infraestructura urbana (casas, drenajes, tendidos eléctricos, escuelas y comedores populares) o de las defensas visibles al ojo del Estado de la organización popular, las resistencias diarias de esta gente logran muchas veces socavar un orden de dominio que las margina y que permite la reproducción del clasismo o de las violencias de género, aun entre los mismos habitantes.

\section{Consideraciones finales}

A manera de recuento breve, en este artículo se visualizaron algunos aspectos referentes a la urbanización informal y a la resistencia de los pobres urbanos en ella. La ZMM, con su marcado crecimiento económico desigual, presenta fenómenos de exclusión de poblaciones marginadas que tienen negados los accesos a trabajos estables, a servicios públicos, a créditos o a otros mecanismos de incorporación ciudadana, como gran parte de la gente de Bellavista. La inseguridad laboral, la precarización de la vida, así como el estigma del que son objeto los habitantes del asentamiento y de otros territorios pobres en la ciudad, merman los derechos de miles de personas que a través de sus resistencias cotidianas buscan hacerse un lugar en la sociedad regiomontana.

Los tránsitos de la gente de Bellavista entre los espacios y las actividades formales e informales, en los cuales se vive la patologización, el empleo político conveniente y la creación de espacios de autonomía, ilustran relaciones de dominación y resistencia sometidas a las tensiones entre el Estado y la sociedad política del asentamiento. Cuando el Estado busca otorgar concesiones bienestaristas que protegen la vida mientras usa convenientemente a los pobres urbanos del asentamiento, cuando no los criminaliza, estos responden con usos tácticos y con proyectos autónomos que persiguen la supervivencia y el reconocimiento de los derechos que como parte de la población mexicana poseen.

Los pobres urbanos de Bellavista traman acciones colectivas que no son impuestas desde fuera ni necesarias siempre de una conducción política ajena. Sus acciones políticas se debaten pragmáticamente entre la resistencia oculta y la actuación abierta que entabla alianzas y confronta o acude al Estado. A su pesar, no obstante, la organización pública y sostenida se les sigue presentando como un lujo escaso, dada su posición de desventaja atizada por el Estado, 
cuestión que reafirma la asimetría de ese vínculo. La resistencia de los habitantes de Bellavista, que trasgrede muchas veces las nominaciones legales con el fin de sobrevivir, no es sin duda heroica. Entre los que resisten, la dominación también se hace presente con un sesgo negativo cargado hacia las mujeres organizadas quienes, pese a todo, ganan terreno público al Estado y a sus parejas conyugales gracias a la movilización y al trabajo disperso y discontinuo de base.

Con la evidencia empírica presentada en este artículo, se constatan, por último, dos aseveraciones que corresponden al aspecto marcadamente político de las demandas y tácticas de las personas de Bellavista. La primera refiere a la legitimización del Estado como la instancia que, pese a la estigmatización y la manipulación, debe proteger a la población, asegurar su bienestar y propiciar las condiciones que permitan el respeto y ejercicio de los derechos (a la vivienda, al trabajo, a la vida). La violencia simbólica se mantiene en este plano, con sus implicaciones sobre la interiorización del dominio y del consentimiento en la búsqueda casi interminable de la inclusión. La segunda, no obstante, alude al potencial liberador de las resistencias cotidianas y de las ocasionales explosiones públicas de organización popular. En el contacto con el Estado, en su confrontación y en la huida de sus intentos de captura, la gente de Bellavista se rebela contra la opresión y por valores que se suponen como comunes a todas las personas: la vida, la dignidad y los derechos.

\section{Referencias}

Aldrete-Hass, J. (1985). Asentamientos ilegales, políticas urbanas y el Estado. Estudios Sociológi$\cos , \operatorname{III}(8), 371-387$.

Alsayyad, N. \& Roy, A. (2006). Medieval Modernity: On Citizenship and Urbanism in a Global Era. Space and Polity, 10(1), 1-20.

Álvarez Enríquez, L. \& Delgado Ramos, G. (2014). Ciudades, gestión, territorio y ambiente. Interdisciplina, 2(2), 9-20.

Aparicio Moreno, C., Ortega Rubí, M. \& Sandoval Hernández, E. (2011). La segregación socio-espacial en Monterrey a lo largo de su proceso de metropolización. Región y Sociedad, XXIII(52), 173-207.

Appadurai, A. (2007). El rechazo de las minorías. México: TusQuets.

Auyero, J. \& Benzecry, C. (2017). The Practical Logic of Political Domination: Conceptualizing the Clientelist Habitus. Sociological Theory, 00(0), 1-21. 
Bayat, A. (2007). Radical Religion and the Habitus of the Dispossessed: Does Islamic Militancy Have an Urban Ecology? International Journal of Urban and Regional Research, 31(3), 579-590.

Bayat, A. (2000). From 'Dangerous Classes' to 'Quiet Rebels'. Politics of the Urban Subaltern in the Global South. International Sociology, 15(3), 533-557.

Bourdieu, P. (2014). Sobre el Estado. Cursos en el College de France (1989-1992. Barcelona: Anagrama.

Bourdieu, P. (2000). La dominación masculina. Barcelona: Anagrama.

Butler, J. (2001). Mecanismos psíquicos del poder. Teorias sobre la sujeción. Madrid: Cátedra.

Certeau, Michel de. (1984). The practice of everyday life. Los Ángeles: University of California Press.

Chatterjee, P. (2004). The Politics of the Governed. Reflections on Popular Politics in Most of the World. Nueva York: Columbia University Press.

Clichevsky, N. (2006). Regularizando la informalidad del suelo en América Latina y el Caribe. Una evaluación sobre la base de 13 paises y 71 programas. Santiago de Chile: ONU/CEPAL.

Das, V. \& Poole, D. (2004). “State and Its Margins. Comparative Ethnographies”. En Veena, D. \& Poole, D. (Eds.). Anthropology in the Margins of the State (pp. 3-34). Santa Fe: School of American Research Press.

Davis, M. (2006). Planet of Slums. Nueva York: Verso.

Diani, M. (2012). Interest organizations in social movements: An empirical exploration. Interest Groups \& Advocacy, 1(1), 26-47.

Dube, S. (2001). Sujetos subalternos. México: El Colegio de México.

Dubet, F. (2015). ¿Por qué preferimos la desigualdad? (aunque digamos lo contrario). Buenos Aires: Siglo XXI.

Duhau, E. (2003). La ciudad informal, el orden urbano y el derecho a la ciudad. Trabajo presentado en el Congreso de la ANPur, Belo Horizonte.

Gal, S. (1995). Language and the 'Art of Resistance'. Cultural Anthropology, 10(3), 407-424.

García Cadena, C. \& Ramírez, E. (2006). "The Effect of the Social Identity, the Political Efficacy and the Causal Attribution on the Social Participation and the Collective Relative Depriva- 
tion of Poor Mexicans”. En García Cadena, C. (Ed.). Psychosocial and Cultural Research on Poverty in Mexico. Nueva York: Nova Science Publishers.

García Ortega, R. (2001). Asentamientos irregulares en Monterrey, 1970-2000. Divorcio entre planeación y gestión urbana. Frontera Norte, 13(2), 119-155.

Garnier, J. (2006). Contra los territorios del poder. Por un espacio público de debates y... de combates. Barcelona: Virus.

González Alcalá, J. (2006). "Consolidation System for Low Income Housing and the Cultural Environment where It Operates”. En García Cadena, C. (Ed.). Psychosocial and Cultural Research on Poverty in Mexico (pp. 121-138). Nueva York: Nova Science Publishers.

Harms, E. (2011). Saigon's Edge. On the Margins of Ho Chi Minh City. Minneapolis: University of Minnesota Press.

Herzer, H., Di Virgilio, M., Rodríguez, M. \& Redondo, A. (2008). ¿Informalidad o informalidades? Hábitat popular e informalidades urbanas en áreas urbanas consolidadas (Ciudad de Buenos Aires). Pampa. Revista Interuniversitaria de Estudios Territoriales, 4(4), 85-112.

Holland, A. (2016). Forbearance. American Political Science Review, 110(2), 232-246.

Hollander, J. \& Einwohner, R. (2004). Conceptualizing Resistance. Sociological Forum, 19(4), 533-554.

Hurtado Arroba, E. (2014). Actores, escenarios y tiempos: algunos desafíos para estudiar la acción colectiva en colonias populares. En Tarrés Barraza, M., Montes de Oca, L. \& Silva, D. (Coords.). Arenas de conflicto y experiencias colectivas. Horizontes utópicos y dominación (pp. 297-349). México: El Colegio de México.

Kessler, G. \& Merklen, D. (2013). 1. Una introducción cruzando el Atlántico. En Castel, R., Kessler, G., Merklen, D. \& Murard, N. Individuación, precariedad, inseguridad. ¿Desinstitucionalización del presente? (pp. 9-31). Buenos Aires: Paidós.

Lombard, M. (2012). Planeación insurgente en asentamientos informales: un estudio de caso en Cali, Colombia. Cuadernos de Vivienda y Urbanismo, 5(10), 246-260.

Lomnitz, L. (1975). Cómo sobreviven los marginados. México: Siglo XXI.

Márquez, F. (2008). Resistencia y sumisión en sociedades urbanas y desiguales: poblaciones, villas y barrios populares en Chile. En Ziccardi, A. (Comp.). Procesos de urbanización de la pobreza y nuevas formas de exclusión social. Los retos de las políticas sociales de las ciudades latinoamericanas del siglo XXI (pp. 347-370). Bogotá: Siglo del Hombre/CLACSO-CROP. 
Mezzadra, S. \& Neilson, B. (2012). Between Inclusion and Exclusion: On the Topology of Global Space and Borders. Theory, Culture \& Society, 29(4/5), 58-75.

Modonesi, M. (2010). Subalternidad, antagonismo, autonomía: marxismos y subjetivación politica. Buenos Aires: CLACSO/Prometeo Libros.

Montaño, J. (1983). Los pobres de la ciudad en los asentamientos espontáneos. México: Siglo XXI.

Noriega, A. (1996, 18 de diciembre). “Aquí hace falta de todo”. Vecinos de colonias del poniente carecen de los servicios más indispensables. El Norte.

osLn (Observatorio de la Sustentabilidad de Nuevo León) (2015). Perfiles demográficos y migración Recuperado el 12 de diciembre de 2015, de http://observatorio.iinso.uanl.mx/index .php/diagnostico/diagnostico-03/diagnostico-0301

OCDE (2015). Estudios de políticas urbanas de la OCDE. México. Transformando la politica urbana y el financiamiento de la vivienda. París: OCDE Publishing.

Ochoa, A. (2016, 12 de junio). Crece mancha urbana mil hectáreas al año. El Norte.

Pereira Leite, M. (2008). Pobreza y exclusión en las favelas de Río de Janeiro. En Ziccardi, A. (Comp.). Procesos de urbanización de la pobreza y nuevas formas de exclusión social. Los retos de las politicas sociales de las ciudades latinoamericanas del siglo XXI (pp. 213-248). Bogotá: Siglo del Hombre/CLACSO-CROP.

Pérez, T. \& Castellano, C. (2013). Creación del espacio público en asentamientos informales: Nuevos desafíos urbanos. Bitácora Urbano Territorial, 2(23), 95-104.

Piven, F. \& Cloward, R. (1979). Poor People's Movements. Why They Succeed, How They Fail. Nueva York: Vintage Books.

Portales, L. (2014). Capital social y pobreza multidimensional, el caso de hogares pobres en Monterrey, México. Convergencia. Revista de Ciencias Sociales, 21(66), 39-63.

Pozas, M. (1990). Los marginados y la ciudad. (Tierra urbana y vivienda en Monterrey). En Zuñiga, V. \& Ribeiro, M. (Comps.). La marginación urbana en Monterrey (pp. 15-58). Monterrey: Universidad Autónoma de Nuevo León.

Quijano, A. (1972). La constitución del "mundo" de la marginalidad urbana. EURE. Revista Latinoamericana de Estudios Urbano Regionales, 2(5), 89-106.

Rangel Hinojosa, A. (2003). Supervivencia y prácticas discursivas. El discurso político de tres liderezas populares. Trayectorias. Revista de Ciencias Sociales, 5(12), 21-33. 
Roy, A. (2011). Slumdog Cities: Rethinking Subaltern Urbanism. International Journal of Urban and Regional Research, 35(2), 223-238.

Sandoval Hernández, E. (2008). Estudios sobre pobreza, marginación y desigualdad en Monterrey. Papeles de Población, 14(57), 169-191.

Scott, J. (2013). Elogio del anarquismo. Barcelona: Crítica.

Scott, J. (2009). The art of not being Governed. An anarchist history of upland Southeast Asia. New Heaven: Yale University Press.

Scott, J. (1998). Seeing Like a State. How Certain Schemes to Improve the Human Condition Have Failed. New Haven: Yale University Press.

Scott, J. (1985). Weapons of the Weak. New Heaven: Yale University Press.

Silva Londońo, D. (2014). Entre clientelismo y contienda. Los desalojos de los comerciantes ambulantes del Centro Histórico de la Ciudad de México (1993, 2007). En Tarrés Barraza, M., Montes de Oca, L. \& Silva, D. (Coords.). Arenas de conflicto y experiencias colectivas. Horizontes utópicos y dominación (pp. 257-295). México: El Colegio de México.

Soldano, D. (2008). Vivir en territorios desmembrados. Un estudio sobre la fragmentación socio-espacial y las políticas sociales en el área metropolitana de Buenos Aires (1990-2005). En Ziccardi, A. (Comp.). Procesos de urbanización de la pobreza y nuevas formas de exclusión social. Los retos de las políticas sociales de las ciudades latinoamericanas del siglo XXI (pp. 37-70). Bogotá: Siglo del Hombre/CLACSO-CROP.

Therborn, G. (2016). Los campos de exterminio de la desigualdad. México: FCE.

Tilly, Ch. (1991). Domination, Resistance, Compliance... Discourse. Sociological Forum, 6(3), 593-602.

Torres Tovar, C. (2009). Ciudad informal colombiana. Barrios construidos por la gente. Bogotá: Universidad Nacional de Colombia.

Turner, J. (1968). Uncontrolled urban settlement: problems and policies. International Social Development Review, (1), 107-128.

Valles Acosta, Y. (2015). Prácticas ciudadanas en la regularización de la tenencia de la tierra. Un caso del área metropolitana de Monterrey. Tesis de Doctorado en Ciencias Sociales con orientación en Desarrollo Sustentable. México: Universidad Autónoma de Nuevo León. 
Valles Acosta, Y. \& Infante, J. (2014). Mujeres y acción colectiva para la regularización de la tierra: un caso de Monterrey, México. Revista de Estudos Feministas, 22(3), 863-884.

Vinthagen, S. \& Johansson, A. (2014). Dimensions of Everyday Resistance: An Analytical Framework. Critical Sociology, version electrónica, 1-19.

Vinthagen, S. \& Johansson, A. (2013). "Everyday Resistance": Exploration of a Concept and its Theories. Resistance Studies Magazine, (1), 1-46.

Wacquant, L. (2014). Marginalidad, etnicidad y penalidad en la ciudad neoliberal: una cartografía analítica. En Tiempos violentos. Barbarie y decadencia civilizatoria (pp. 177-211). Buenos Aires: Herramienta.

Wacquant, L. (2010). Las dos caras de un gueto. Ensayos sobre marginalización y penalización. Buenos Aires: Siglo XXI.

Yiftachel, O. (2009a). Theoretical Notes on "Gray Cities": the Coming of Urban Apartheid? Planning Theory, 8(1), 87-99.

Yiftachel, O. (2009b). Critical theory and "gray space". Mobilization of the colonized. City, $13(2-3), 240-256$

Ziccardi, A. (2008). Pobreza y exclusión social en las ciudades del siglo xxi. En Ziccardi, A. (Comp.). Procesos de urbanización de la pobreza y nuevas formas de exclusión social. Los retos de las políticas sociales de las ciudades latinoamericanas del siglo XXI (pp. 9-36). Bogotá: Siglo del Hombre/CLACSO-CROP.

Zúñiga, V. (1990). ¿Para qué sirve la escuela? Marginación, educación escolar y movilidad intergeneracional en Monterrey. En Zúñiga, V. \& Ribeiro, M. (Comps.). La marginación urbana en Monterrey (pp. 15-58). Monterrey: Universidad Autónoma de Nuevo León. 